\title{
O CONSUMO DE DROGAS PELA JUVENTUDE BRASILEIRA
}

KOPANAKIS, Annie Rangel*.- Mestre em Ciências Sociais pela Unesp-Araraquara; BATONI. Bruna Risquioto. - Especializanda em Habilidades Sociais - Universidade de Araraquara; OLIVEIRA, Debora Ortolan Fernandes de.- Especialista em Psicologia em Saúde Pública pela Univerdade Estadual Paulista. *Autor para correspondência e-mail: annie_rk@hotmail.com

\section{Artigos de Revisão}

\section{Resumo}

Recebido em: 10/10/2017

O consumo de drogas pela juventude tem sido foco de debates políticos e alvo de estudos acadêmicos que buscam compreender esse fenômeno na sociedade brasileira. Este artigo propõe uma reflexão sobre significado da disposição subjetiva de consumir drogas na juventude contemporânea. Objetiva-se discorrer sobre o consumo de psicoativos por jovens, através de uma discussão fundamentada em uma leitura sociológica e psicanalítica do uso de substâncias psicoativas, sobretudo o álcool. A metodologia aplicada foi um estudo exploratório com breve revisão da literatura sobre drogas, juventude e adolescência que fundamentou a presente discussão embasada à luz da psicanálise e da sociologia. Os resultados encontrados indicaram que a utilização de álcool e outras drogas, pela juventude brasileira, está associado a paradigmas da sociedade de consumo, estando relacionado a uma busca por bem-estar e aceitação social.

Palavras-chave: Psicanálise; Juventude; Drogas.

\section{THE USE OF DRUGS BY BRAZILIAN YOUTH}

\section{Abstract}

The use of drugs by youth has been the focus of political debates and objective of academic studie that seek to understand this type of phenomenon in Brazilian society. This article proposes a reflection on the meaning of the subjective disposition of consuming drugs in contemporary youth. The objective of this study is to discuss psychoactive use by young people through a discussion based on a sociological and psychoanalytic analysis of the use of psychoactive substances, especially alcohol. The methodology applied is that of an exploratory study with a review of the literature on drugs, youth and adolescence that base the present discussion based in the light of psychoanalysis and sociology. The results showed that Brazilian youth consume alcohol and other drugs in search of well-being and social acceptance.

KeYwORDs: Psychoanalysis;Youth; Drugs. 
INTRODUÇ̃̃o

Interessa a este artigo o significado da disposição subjetiva de consumir drogas na sociedade contemporânea, considerada em algumas pesquisas, como comportamento individual. Objetiva-se discorrer sobre o consumo de psicoativos por jovens, através de uma

discussão fundamentada na sociologia e na psicanálise acerca do consumo de substâncias psicoativas, sobretudo o álcool.

De acordo com dados da Secretaria Naciona Antidrogas, obtidos a partir do $1^{\circ}$ Levantamento Nacional sobre os Padrões de Consumo de Bebida alcoólica na População Brasileira, os adolescentes (entre 14 e 17 anos) estão consumindo bebidas alcoólicas cada vez mais cedo. Estes dados obtidos também revelam uma modalidade de consumo de risco, denominada "beber em binge", que significa o consumo de quatro doses ou mais por mulheres e cinco doses ou mais por homens, em uma única ocasião (LARANJEITA et al, 2007; PINSKY et al, 2010).

Há, ainda hoje, pouca compreensão das experiências de jovens, de ambos os sexos, com relação ao consumo lúdico de drogas e bebidas alcoólicas. Para vários autores o comportamento de consumir bebidas alcoólicas e drogas diversas está associado a celebrações, eventos culturais, sociais, entre outros. Em contrapartida, nos cenário comemorativos, o consumo de bebidas alcoólicas está como responsável por 3\% de todas as mortes mundiais (MELONI; LARANJEIRA, 2004).

Em relatórios internacionais, o consumo de bebida alcoólica está associado ao de drogas ilícitas, como a isso se refere o lançado, em 2012, pela ONU. O uso de drogas ilícitas se realiza na maior parte das vezes em grupos, especialmente de jovens, mas o consumo anual de bebida alcoólica é oito vezes maior que o de drogas ilícitas. As primeiras experiências com substâncias psicotrópicas ocorrem, em sua maioria, nos primeiros anos da juventude, em uma referência aos 15 anos, e o www.cebrid.epm.br/index.php) consumo de bebida alcoolica aumenta e acompanha o avanco da idade. Ainda causa preocupação o dado que "os comportamentos aditivos em adolescentes são atualmente um problema de saúde pública em todo o mundo" (WORLD DRUG REPORT, 2012, p.14).

Mas poucos estudos vêm sendo realizados sobre o consumo de bebida alcoólica, junto aos grupos de jovens, sem associá-lo ao consumo de outras substâncias, ou comportamento de risco. A ausência desses estudos específicos ofusca, no entendimento das autoras, a compreensão da relação entre bebida alcoólica e formação da subjetividade juvenil e na decorrente sociabilidade em outros ambientes.

Nas denominadas sociedades do espetáculo e mal-estar, cada vez mais o consumo de substâncias psicoativas se realiza comercialmente, como recurso para superação de males subjetivos (COSTA, 2004; BIRMAN, 2006). Esses ambientes, que abrigam esse tipo de consumo deveriam merecer especial atenção das pesquisas em Ciências Sociais e Psicologia, com vistas à projeção de práticas preventivas e para contribuir para a crítica das relações sociais no tempo livre juvenil.

Além da compreensão da subjetividade juvenil, o estudo das relações sociais existentes entre jovens, pode levar a uma caracterização cultural e ideológica do papel que o consumo de substâncias psicoativas desempenham, na sua integração no universo das relaçoes mercantis. São esses os dois aspectos mais relevantes no presente artigo.

Dados do CEBRID', segundo o "II Levantamento Domiciliar sobre o Uso de Drogas Psicotrópicas no Brasil”, realizado em 2005 apontam para um aumento de consumo de bebidas alcoólicas pela população brasileira nos últimos quatro anos. Mesmo com a ressalva de esse centro utilizar parâmetros etários para identificar adolescentes e jovens, anteriores ao Estatuto da Juventude (15 documento. $\mathrm{O}$ consumo de bebida alcoólica entre os adolescentes estudados de 12 a 17 anos foi de 54,3\% e entre os jovens de 18 a 24 anos foi de 78,6\%. A pesquisa revelou que só $5,7 \%$ dos entrevistados nas faixas etárias entre 12 e 17 anos identificaram problemas associados ao consumo de bebidas alcoólicas e $12 \%$ entre os entrevistados de 18 a 24 anos (CARLINI, 2006).

O "I Levantamento Nacional Sobre o Uso de Bebida alcoólica, Tabaco e Outras Drogas Entre Universitários das 27 Capitais Brasileiras", de 2010 revela que a bebida alcoólica é a substância psicoativa mais utilizada entre estudantes universitários. A partir das entrevistas realizadas, constatou-se que um em cada quatro estudantes universitários brasileiros mencionou ao menos uma ocasião de beber pesado episódico, nos trinta dias anteriores à entrevista; e um em cada três mencionou consumir bebidas alcoólicas dessa forma no último ano (ANDRADE; DUARTE; OLIVEIRA, 2010)

Assim, observa-se que frenético consumo de bebidas alcoólicas por esses jovens remete a uma grande preocupação social. A maioria dos universitários consome bebida alcoólica de forma recorrente e subentende-se que são vulneráveis ao início e uso contínuo dessa substância (ANDRADE; DUARTE; OLIVEIRA, 2010).

\section{Metodologia}

A pesquisa foi fundamentada em uma revisão bibliográfica na base de dados Scielo Brasil (http:// www.scielo.br), no mês de janeiro de 2018, com a intenção de mapear artigos publicados nos últimos 10 anos, para fundamentar a pesquisa. Utilizouse as seguintes palavras-chaves: com primeiro termo "drogas" e segundo termo "juventude" ou "adolescência", a fim de investigar o que a literatura acadêmica demonstra acerca do tema ate o momento.

As palavras-chaves "drogas" e segundo termo "juventude" geraram 20 artigos e "drogas" segundo termo "adolescência" 151 artigos, sendo 171 artigos para análise.

Os resultados desta busca sofreram algumas exclusões, tais como: resultados repetidos, com data anterior a 2008, em língua estrangeira, textos sem relação com o tema: redações sobre legislação e projetos de lei, tráfico de drogas e outros atos infracionais, tratamentos e serviços de saúde e saúde mental, além de intervenções que não fossem da psicologia, dando um total de 29 artigos.

Todos os resumos dos 29 artigos foram analisados a fim de verificar a relação com o tema de interesse: compreender o consumo contemporâneo das drogas. Foram excluídos artigos que tinham relação com drogas e intervenções escolares e projetos sociais interventivos, gerando um total de 16 artigos.

E mediante a isto, 16 artigos foram lidos para uma breve dissertação dos resultados com os principais tópicos encontrados. As discussões feitas a partir destes textos tiveram contribuições de autores da sociologia e psicanálise.

\section{Resultados e Discussões}

As substâncias psicoativas estão presentes na humanidade desde seu primórdio e vem sendo produzidas e consumidas como a maioria dos outros bens presentes nas sociedades. Contudo o uso dessas substâncias, também chamadas de drogas, tem atingido grandes proporções na sociedade brasileira e desde então, detido a atenção da mídia e política (CARLINI-MARLATT, 2006; COSTAROSA, 2012).

$\mathrm{Na}$ atualidade, enxergar que as pessoas estão vivendo numa era de crises de valor tornou-se comumente difundido. A validação científica ocupou o lugar da autorrealização, antes preenchido por representações como: família, trabalho, política e religião. Essa nova configuração, segundo os críticos modernos, se dá pela globalização econômica que culminou na desestruturação dos antigos parâmetros que direcionavam a formação das identidades. O que era configurado através de preceitos morais e valores ideais tornou a sofrer avaliações pela esfera científica, que agora fala na posição da verdade. Todo o sentimentalismo, as qualidades morais, o desenvolvimento da alma, traduziam os autocuidados. Agora o cuidar de si está voltado ao cuidado com o corpo e corresponder 
a essa praxe que direciona o indivíduo para a felicidade e realização de seus anseios, ou não.

Dentre as drogas preferencialmente utilizadas por jovens, destaca-se o álcool. Segundo Malta et al (2014) é importante considerar o consumo de álcool na adolescência como fenômeno complexo, com multi fatores e determinantes sociais (MALTA et al, 2014). É visto, que os maiores compradores destas bebidas são jovens, independente da nacionalidade ou cultura, também na grande maioria dos países o consumo de substâncias psicoativas demonstra um equilíbrio entre as populações masculinas e femininas. As propagandas sobre bebidas alcoólicas tendem sempre a demonstrar o lado bom e os benefícios que seu consumo trazem para o usuário Elas são permeadas pela criatividade, pessoas "se dando bem na vida" e momentos de lazer ou relaxamento. Além disto, ousam na sensualidade feminina e as propagandas vendem a beleza e o lazer como objetos entrelaçados ao produto Observa-se que essa ideologia comporta-se como algo que o consumidor deseja, em tempos de uma sociedade permeada pelo estresse e culto a perfeição estética (OLIVEIRA et al, 2011).

Para Carlini-Marlatt (2006) a indústria de bebidas alcoólicas tem como foco principal os jovens. A população jovem é tida por "fatia do mercado" facilmente atingível pelas mensagen da mídia, que unem esse público ao consumo de bebidas alcoólicas como importante aspecto da formação da identidade de uma geração. Registrese a ausência de políticas públicas que sejam referência de proteção efetiva desta população, quando o assunto é a voracidade das indústrias em criar consumidores permanentes. A lei que proíbe a venda de bebidas alcoólicas a menores de idade tem gerado pouca fiscalização, como pode se observar no cotidiano. É claro que o potencial de consumo jovem é explorado por várias outras vertentes do mercado como tema de marketing; contudo, o consumo em potencial de bebidas alcoólicas, diferentemente dos outros produtos que não exercem influência psicoativa, reflete- se em problemas de saúde e sociais que podem estar vinculados a uma tentativa de lidar com o chamado mal-estar-social (CARLINI-MARLATT, 2006 apu ROOM et alii, 2002; COSTA, 2004).

Ainda sobre o culto estético, outra característica associada ao uso de drogas, seria o imaginário social e o desejo de se manter jovem. O termo juventude também pode ser relacionado àquele que inova e questiona os meios tradicionais. Os jovens da periferia e que são vistos a margem da sociedade tendem a ampliar o uso de drogas, por uma questão de confrontamento social juvenil e depois passam a utilizá-la como fuga para os próprios problemas da realidade. Isto, demonstra o quanto o social e a rede de apoio, amigos e ambiente, acaba contagiando a subjetividade do sujeito (BARDI; MALFITANO, 2014).

Em contrapartida ao uso de bebidas em que é visto equilíbrio entre os gêneros, o uso de drogas ilícitas, tem como um agente agravante o pressuposto de atribuir caráter masculino ao usuário, como se o utilizar drogas deixasse a pessoa mais forte para as pessoas de seu grupo social, e isto é visto maior imaginário de poder em populações de baixa renda (GRANJA et al, 2015, BITTENCOURT; FRANCA; GOLDIM, 2015).

Uma questão também enfatizada são as relações familiares e seus conflitos, quanto menor a rede de apoio ou disfuncional, maior as chances de levar o jovem ao uso de drogas (ROEHRS; LENARDT; MAFTUM, 2008). Este fato evidencia-se em meninas que sofrem violência psicológica po parte de membros da família e pressão social, retomando o contexto da droga como dispositivo de fuga da realidade (GUIMARAES et al, 2009). Outro fator associado ao uso de álcool e outras drogas é o bullying. Pode-se induzir que a violencia em si é tida como um dispositor para aquele que sofre procure meios de fugir da realidade vivida (HORTA, 2018).

Além do mais, pais que tem um monitoramento afetivo sobre a vida dos filhos reduzem a prática 作 filhos. O monitoramento é feito por meio de saber as atividades que estes praticam, quem são seus amigos, ter tempo livre para interagir com eles, saber sobre sua gestão financeira e que dão apoio para a resolução de problemas (PAIVA; RONZANI, 2009, MALBERGIER; CARDOSO ;AMARAL, 2012).

A fase da adolescência é permeada por inúmeras de criança e se vê introduzido ao mundo adulto. $\mathrm{O}$ jovem adulto universitário, por exemplo, também tem inúmeras ansiedades devidas ao estresse, pressão, expectativa de futuro. A sociedade atual emerge transtornos ansiosos a vários públicos. $\mathrm{O}$ uso de álcool e tabaco tem grande relação com a busca pelo relaxamento, mas outras drogas também vem sendo usadas, principalmente pelo adolescente (LOPES; REZENDE, 2013).

Estes argumentos vão de encontro ao fato que adolescência é um momento de desenvolvimento em que o corpo e a mente estão em transformação e são conflituosos entre si, necessitando de maior apoio das pessoas que estão entorno do adolescente. Assim, a droga entra como algo para funciona a partir do Princípio do Prazer fazendo uma redução de tensão psíquica (ADESSE; SANTOS CARDOSO, 2014, MACEDO; CONCEICAO 2015).

Deste modo, o recurso ao uso de drogas na fase da adolescência pode ser compreendido como uma ligação entre várias operações psíquicas atuantes nesta fase, por exemplo, as negativas relacionadas problemas familiares, relacionamento ruim com a escola, grupo de amigos disfuncionais, facilidade de acesso às drogas, eventos estressores, principalmente recorrentes e as positivas como estratégias de sublimação e relaxamento como grupos de esporte, arte e exposição de sentimentos, autoestima elevada, relação boa com os familiares, escola, amigos, comunidade e religião (RAUPP; MILNITSK Y-SAPIRO，2009,ZAPPE，\& DELL'AGLIO, 2016).

urandir Freire Costa debateu a ruptura dos modelos de bem-estar, que permitiu a aceitação de práticas, antes consideradas imorais como a liberdade sexual, religiosa e também a complacência com consideradas transgressões morais. Nesse cenário a saúde com o corpo tornou-se tema prioritário de objeto a ser preservado (COSTA 2004).

Com essa ruptura, os desejos estão voltados para aquilo que pode ser experimentado sensorialmente, como prazeroso e deleitável. Esses mesmos desejos não correspondem mais a almejar e projetar futuro, o que leva tempo, exige esforço, ou não traz o prazer esperado. Esse ideal de prazer não sustenta conquista de bem-estar e consequente formação de uma consciência do presente, resultando na produção cultural de padrões desviantes, dentre eles, a estúlcia (COSTA, 2004):

Os estultos são, então, tipificados segundo o grau ou a natureza do desvio em: a) dependentes ou adictos, isto é, os que não controlam a necessidade de drogas lícitas e ilícitas; de sexo; de amor; de consumo; de exercícios físicos; de jogos de azar; de jogos dé or desregulados, isto é, os que não podem moderar o ritmo ou a intensidade das carências fisicas (bullmicos, anorexicos) ou mentais (portadores de síndrome de pânico, fobias sociais); c) inibidos, isto é, os que se intimidam com o mundo e não expandem a força de vontade, como os distímicos, os apáticos, os não assertivos, os "não assumidos"; d) estressados, isto é, os que não sabem priorizar os investimentos afetivos e desperdicam ench energia,

e) deformados, isto é, os que ficam para trás na maratona do fitness: obesos; manchados de pele; sedentários; envelhecidos precocemente; tabagistas; não- siliconados; não-lipoaspirados, etc." (Jurandir Freira Costa, O vestígio e a aura, corpo e consumismo na moral do espetáculo, p. 195/196, 2004).

Esses modos de ser expressam formas, também juvenis, de mal-estar contemporâneas, que sofreram um processo de mudança. Hoje o mal-estar se 
encontra nos registros do corpo, da ação e do sentimento e ocupa o lugar preenchido até então pelos conflitos psíquicos recobertos de impulsos e implicações morais. Dessa forma, o mal-estar se tornou um importante cenário para a compreensão das subjetividades juvenis contemporâneas.

Para os cidadãos viventes na pós-modernidade, o corpo revela seu único bem é tratado como principal foco do mal-estar. $\mathrm{O}$ que faz com que se torne impossível separá-lo das estratégias publicitárias que oferecem uma boa alternativa para o stress permanente na contemporaneidade. A ação revela a imposição da hiperatividade, que implica no agir frequente, sem pensar sobre os objetivo que seriam alcançados com essa ação, mas para aliviar o excesso das chamadas angústias que as individualidades produziram

Ainda considerando a ação, se faz necessário falar sobre a compulsão que demonstra a repetição do mesmo, ou seja, a busca permanente do que nunca é alcançado. Uma das compulsões mais comuns do mal-estar é o uso de drogas, dentre elas as bebidas alcoólicas (BIRMAN, 2006)

Com as novas formas de mal-estar social os indivíduos tendem a adquirir os novos produtos que prometem sanar esse desconforto. $\mathrm{O}$ consumo afirmou seu lugar de nova mediação do sujeito na sociedade do modo capitalista de produção globalizado: "consumo, logo existo": "Eis a sagacidade com que este e seu braço armado, a tecnociência, souberam ler a especificidade não mais apenas do indivíduo liberal e daquilo que o caracteriza como, existência no campo do sentido, mas das novas figuras do mal-estar da civilização"(COSTA- ROSA, 2012, pg 79).

Estes argumentam geram a percepção que as drogas passam a amenizar as transformações advindas do mal-estar social através, da busca permanente de prazer. Alvo ideal para o modo capitalista de produção que compreende essa necessidade e fabrica esses objetos de consumo.

Em sua obra O Mal-Estar na Civilização, Freud demonstra que recorrer às substâncias psicoativas seria uma medida que ocorre como resposta do sujeito para o mal-estar sentido. Isso é parte do processo de formação das sociedades e da constituição psíquica do ser humano. Um dos métodos mencionados por Freud para suportar o mal-estar gerado pelas construções das civilizações, que sobrepõe ao homem o sacrifício da sexualidade da agressividade, que são inerentes ao ser humano é o uso de substâncias tóxicas. Essas substâncias, quando em contato com o organismo ocasionam sensações de prazer e culminam na incapacidade de receber impulsos desagradáveis (FREUD, 1927 1931/2006).

Joel Birman (2001), em outra obra trata essa argumentação de Freud como a crítica psicanalítica da modernidade e, a partir dessa visão, traz a reflexão de que os sujeitos modernos fazem parte de um contexto que abriga novas formas de subjetivação, remetendo a condição trágica do mundo moderno (BIRMAN, 2001).

A atualidade tem trazido alguns sintomas com mais frequência e incômodo, se comparados ao século passado. Um desses é a drogadição e, em seu conjunto, traz o desafio de repensar a subjetividade. O mundo mercantil tomou o lugar das formações moralistas, antes preenchidos por padrões de comportamento definidos em âmbito familiar. " $\mathrm{O}$ self- made-man" dos primórdios do capitalismo deixou de ser o trabalhador esforçado e econômico para se tornar o gestor de seu próprio "perfil de consumidor" a partir de modelos em oferta no mercado"” (KEHL, 2009).

Vive-se uma cultura das drogas, na qual estão inclusas as bebidas alcoólicas e o fumo. Os indivíduos habituam-se à intoxicação, pois essas substâncias psicoativas (drogas lícitas,ilícitas e psicofármacos) são elementos dos estilos contemporâneos de existência. No entanto, vazio sentido nessa configuração de mal-estar não é suportado pela subjetividade contemporânea, tendo que ser preenchido pelas drogas, comidas e consumos genéricos, mas compulsivos. Forma-se, então, uma aliança perfeita: a busca por lucro obtido através de produtos que "combatem" o mal-estar vivido pela sociedade e indivíduos, em particular, cada vez mais seduzidos por esses produtos. Desse modo existe uma dificuldade em se separar o malestar sentido nas estratégias publicitárias, que envolvem a sociedade atualmente e o mal- estar subjetivo da incapacidade de projeção de futuro, entre outros. As drogas que são vistas hoje em dia, fazem parte de um estilo contemporâneo de existência (BIRMAN, 2006).

A formação da identidade está hoje afetada pelo mercado, onde os objetos de consumo são fundamentais para a construção de referências subjetivas. Os planos de vida individuais não conseguem ocupar uma posição confortável na forma atual de sociedade e não conseguem ultrapassar as barreiras invisíveis na nova dinâmica social (BAUMAN, 1998). O sujeito deve crer no seu esforço, sucesso e força de vontade e, caso haja um fracasso, o corpo deve adoecer fisicamente.

Por uma via, o indivíduo se enxerga onipotente, detendo a crença de que consegue instituir a mora a partir das experiências corpóreas. E páreo a isso experimenta a sensação de impotência, ao ser levado a acreditar que o sentido de seu sofrimento é genético ou neuro- hormonal. Todo esse enfoque no corpo e no gozo das sensações ameniza a importância emocional de outro humano. Embora, todos precisem do reconhecimento, num outro, para assegurar-se de seus valores e ideais. O pape da moda e figuras veiculadas pela publicidade não dão espaço para os modelos pessoais de moral e apenas representa um ideal que não se importa com as peculiaridades dos sujeitos aos quais e direciona (COSTA, 2004).

Caccia-Bava (1999) em seu ensaio "Solidariedade, sociabilidade e ética política: temas clássicos ou contemporâneos?" traz uma reflexão sobre o conceito de sociabilidade na sociedade contemporânea. A sociabilidade reduziria os indivíduos a vítimas do mercado capitalista, das relações mercantis, mediadas sempre pelo ideal do lucro. Trazendo essa perspectiva ao comportamento grupal de jovens universitários, o consumo nas baladas é uma medida de viver a sociabilidade e o lucro seria o prazer atingido. Essa poderia ser uma faceta que reflete numa espécie do mal-estar sentido pelo jovem brasileiro, que busca sua identidade grupal no consumo de substâncias psicoativas. Se na juventude, o papel do grupo se faz muito importante na tentativa de romper com os modos de ser familiares, através das relações extra- familiares a crise política é mais facilmente perfilhada, levando a uma falta de confiança nos poderes constituído (WINNICOTT, 1961; ZARIFIAN apud CACCIABAVA, 1999)

No panorama das drogas ilícitas, que como citado também são elementos corroborativos do mal-estar contemporâneo, se realiza, também, a reprodução de manifestações mercantis. O sucesso do mercado das drogas tem por razão sua grande ocupação nos espaços preenchidos pelos jovens, po livre. Como afirma Harding cada ritmo, uma droga correspondente". Por isso, se fazem necessárias pesquisas nessa área, abrigando espaços recentemente constituídos, para a realização do tempo livre juvenil. (HARDINGHAUS, 1995 apud CACCIA-BAVA, 2006)

Pacheco, 2007, em seu artigo "Toxicomania: um modo fracassado de lidar com a falta estrutural do sujeito e com as contradições da sociedade", traz a reflexão de que várias transformações históricas tiveram como seu berço o capitalismo, que transformou as relações sociais e forças produtivas. Na civilização ocidental a sociedade é constituída em cima dos pilares da "mercantilização" das relações sociais, em que os sujeitos se constituem como ferozes consumidores dos objetos de consumo. A drogadição veio a ser um eficaz modo de movimentar o sistema atuando numa relação intensa entre o objeto e a pulsão. $\mathrm{O}$ autor cita: "Da mesma maneira que a Revolução Francesa marca o êxito da instauração do modo de produção capitalista e o fracasso dos seus ideais de Liberdade, Igualdade e Fraternidade, a toxicomania atesta o sucesso do ideal de consumo e a falência do que esse ideal insinua como promessa" (PACHECO, 2007, p.36).

Consideramos, assim, que a questão do uso VoL. 21, N.2, 2018 
uma problemática de saúde, mas também social e econômica, sendo que não é possível pensar na questão de saúde sem considerar esses outros fatores citados nos artigos estudados.

\section{Considerações Finais}

O consumo de substâncias psicoativas por joven brasileiros está vinculado a características culturais e sociais, que propõe o uso de drogas, sobretudo as bebidas alcoólicas, a partir de uma imagem de que o consumo gera satisfação e sensação de pertencimento a espaços e grupos.

Como um produto da sociedade do consumo, o álcool e outras drogas são inseridas no âmbito social através de uma oferta imaginária de bemestar. Os problemas de saúde pública, encontram no consumo juvenil dessas substâncias um desafio e movimentam estudos que preocupam-se em trazer para o âmbito acadêmico compressões desse fenômeno.

Compreende-se, através da bibliografia estudada, que não é possível pensar o uso de drogas sem considerar a sociedade contemporânea e seus desafios. Deste modo, se faz necessário olhar para as consequências, inclusive a sociabilidade, da juventude, pois foi visto que o consumo de drogas não é apenas um recurso de superação dos males sociais e subjetivos, mesmo que tal consumo possa, ilusoriamente, parecer contribuir para lidar com questões sociais.

A questão que emerge, não trata o consumo algo inerente a humanidade, mas o enfoque no consumo das substâncias através dos pressupostos da sociedade de consumo que incita que a droga é solução ao mal-estar social. Considera-se que o uso de drogas, imerso nesse contexto, trata-se de uma reprodução do consumo em uma sociedade que valoriza bens materiais, culto a perfeição estética, poder e fuga da realidade problemática em busca da felicidade ilusória.

Desta forma, faz-se necessário um olhar para este fenômeno social e para a ausência de políticas públicas de proteção desta população jovem. Além da necessidade de ampliar a compreensão do papel cultural e ideológico que o consumo dess na subjetividade da juventude. Vale ressaltar a importância dos estudos atentarem-se tanto aos fatores de risco do consumo de drogas, quanto os fatores de protetivos, conforme foi discutido no presente artigo.

\section{REFERÊNCIAS}

ADESSE, D.; SANTOS, V.; CARDOSO M. Drogadicção e adolescência: o "corpo do transbordamento". Rev. latinoam. psicopatol. fundam., São Paulo, v. 17, n. 3, p. 544-556, Sept. 2014

ANDRADE, A.G; DUARTE, A, V; OLIVEIRA, L.G. (Org.). I Levantamento Nacional Sobre o Uso de Bebida alcoólica, Tabaco e Outras Drogas Entre Universitários das 27 Capitais Brasileiras. Brasília: SENAD, 2010. 282 p.

BARDI, G.; MALFITANO, A. religiosidade e prostituição: os agenciamentos de um ser ambivalente. Saude soc., São Paulo, v. 23, n. 1, p. 42-53, Mar. 2014

BAUMAN, Z. O mal-estar da pós-modernidade. 1. ed. Rio de Janeiro: Jorge Zahar Editor, 1998. $276 \mathrm{p}$

BIRMAN, J. Arquivos do mal-estar e da resistência. 1. ed. Rio de Janeiro: Civilização Brasileira, 2006. 418 p.

BIRMAN, J. Mal-estar na atualidade: a psicanálise e as novas formas de subjetivação.7.ed. Rio de Janeiro: Civilização Brasileira, 2009. 304 p

BITTENCOURT, A.; FRANCA, L.; GOLDIM, J. relacionados ao uso de drogas. Rev. Bioét. Brasília, v. 23, n. 2, p. 311-319, Aug. 2015
CACCIA-BAVA, A. Sobre as políticas locais de segurança para os jovens. In: Política \& Sociedade: Revista de Sociologia Política, v.5, n.8, p.59-87. Florianópolis: UFSC/ Cidade Futura, 2006.

Solidariedade, sociabilidade e ética política: temas clássicos ou contemporâneos? In: D'INCAO, M. A. (Org) Sociabilidade: espaço e sociedade. São Paulo: Grupo Editores, 1999.

CARLINI, E; et al. II levantamento domiciliar sobre 0 uSo de drogas psicotrópicas no Brasil: estudo envolvendo as $\mathbf{1 0 8}$ maiores cidades do país. 2005. São Paulo: Páginas \& Letras, 2007. v. $01.472 \mathrm{p}$.

CARLINI-MARLATT, B. Jovens e drogas: saúde, politica neoliberal e identidade jovem. In P.P.M. Branco; H.W.Abramo. (org). Retrato da Juventude Brasileira: Análise de uma Pesquisa Nacional. Ed. Fundação Perseu Abramo, 2006. 303-319 p

COSTA, J.F. O VESTÍGIO E A AURA: corpo e consumismo na moral do espetáculo. 1.ed. Rio de Janeiro: Garamond, 2004. 243 p.

COSTA-ROSA, A. Subjetividade e uso de drogas. In: CONSELHO REGIONAL DE PSICOLOGIA

FREUD, S. O Futuro de uma Ilusão, o Mal-Estar na Civilização e outros trabalhos (1927-1931). 1.ed. Rio de Janeiro: Imago, 2006. v. XXI. 299 p.

GUIMARAES, A. et al. Aspectos familiares de meninas adolescentes dependentes de álcool e drogas. Rev. psiquiatr. clín., São Paulo, v. 36, n. 2, p. 69-74, 2009

GRANJA, Edna et al . O (não) lugar do homem ovem nas políticas de saúc coletiva, Rio de Janeiro, v. 20, n. 11, p. 3447-3455, SP. Álcool e outras drogas. Ed. x, 2012. 75-90 p. Brasil: aproximações genealógicas. Ciênc. saúde

Nov. 2015.

HORTA, C. et al. Bullying e uso de substâncias psicoativas na adolescência: uma revisão sistemática. Ciênc. saúde coletiva, Rio de Janeiro, v. 23, n. 1, p. 123-140, Jan. 2018

KEHL, M.R. Sintomas no mercado. 2004 Disponível em: <http://www.mariaritakehl.psc.br/ conteudo. php?id=75> Acesso em 18 jan 2018.

LARANJEIRA, R; et al.. Primeiro levantamento nacional sobre os padrões de consumo de bebida alcoólica na população brasileira. Brasilia: SENAD, 2007. $76 \mathrm{p}$

LOPES, A.; REZENDE, M. Ansiedade e consumo de substâncias psicoativas em adolescentes. Estud. psicol. (Campinas), Campinas, v. 30, n. 1, p. 4956, Mar. 2013.

MELONI, J.N; LARANJEIRA. R. Custo social e de saúde do consumo do álcool. In: Revista Brasileira de Psiquiatria., São Paulo, v.26, p. 7-10, 2004.

MALBERGIER, A.; CARDOSO, L.; AMARAL, R.do. Uso de substâncias na adolescência e problemas familiares. Cad. Saúde Pública, Rio de Janeiro, v. 28, n. 4, p. 678-688, Apr. 2012.

MALTA, D. et al. Exposição ao álcool entre escolares e fatores associados. Rev. Saúde Pública, São Paulo, v. 48, n. 1, p. 52-62, Feb. 2014.

OLIVEIRA, M.; ROMERA, L.; MARCELLINO, N. Lazer e juventude: análise das propagandas de cerveja veiculadas pela televisão. Rev. educ. fis. UEM, Maringá, v. 22, n. 4, p. 535-546, Dec. 2011. 
APLICAÇÃO DA CLASSIFICAÇÃO INTERNACIONAL DE FUNCIONALIDADE, INCAPACIDADE E SAÚDE (CIF) EM SAÚDE DO TRABALHADOR

RAUPP, L.; MILNITSKY-SAPIRO, C. Adolescência, drogadição e políticas públicas: recortes no contemporâneo. Estud. psicol. (Campinas), Campinas , v. 26, n. 4, p. 445-454, Dec. 2009.

ROEHRS, H.; LENARDT, M.; MAFTUM, M. Práticas culturais familiares e o uso de drogas psicoativas pelos adolescentes: reflexão teórica. Esc. Anna Nery, Rio de Janeiro, v. 12, n. 2, p. 353-357, June 2008.

WINICOTT, D.W. Adolescência: transpondo a zona de calmarias. In: Winnicot. A família e o desenvolvimento individual, 1961. 4.ed. São Paulo, SP: Martins Fontes, 2011. 247p.

ZAPPE, J.; DELL'AGLIO, D. Variáveis pessoais e contextuais associadas a comportamentos de risco em adolescentes. J. bras. psiquiatr., Rio de Janeiro, v. 65 , n. 1, p. 44-52, Mar. 2016.

Objetivo: Identificar a utilização da Classificação internacional de funcionalidade, incapacidade e saúde na área de saúde do trabalhador, buscando sua aplicação na avaliação da capacidade funcional de trabalhadores, em exames admissionais, periódicos e demissionais, e também na realização de perícias judiciais trabalhistas. Metodologia: Foi realizada uma revisão da literatura utilizando-se os unitermos "Classificação Internacional de Funcionalidade, Incapacidade e Saúde" e "trabalho" nas bases de dados SciELO, Lilacs e Biblioteca Virtual em Saúde (BVS) os unitermos "International Classification of Functioning, Disability and Health" and "workers" na PubMed. Foram selecionados artigos publicados entre 2005 e 2016. Resultados: Foram incluídas 16 referências, nos idiomas português e inglês, que abordaram a utilização da CIF na área de saúde do trabalhador, independente do tipo de aplicação. Considerações Finais: A busca pela operacionalização e simplificação da Classificação internacional de funcionalidade, incapacidade e saúde permanece como um foco importante dos estudos que objetivam a sua utilização na avaliação da funcionalidade e das incapacidades dos trabalhadores, sendo a saúde do trabalhador uma das áreas promissoras de aplicação da CIF.

PalaVRaS-Chave: Classificação internacional de funcionalidade; Incapacidade e saúde; Trabalho; Saúde do trabalhador.

USE OF THE INTERNATIONAL CLASSIFICATION OF FUNCTIONING, DISABILITY AND HEALTH (ICF) IN OCCUPATIONAL HEALTH

- Objective: Identify the use of the International Classification of Functioning, Disability and Health in the occupational health area, searching for its application in the evaluation of the functional capacity of workers, in admissional, periodical and demissional exams as well as in judicial labor investigations. Methodology: a literature review was made using the expressions "Classificação Internacional de Funcionalidade, Incapacidade e Saúde" (International Classification of Functioning, Disability and Health) and "trabalho" (work) in the databases SciELO, Lilacs and Virtual Health Library (VHL). Both "workers" and "International Classification of Functioning, Disability and Health" in PubMed. Were selected articles published between the years 2005 to 2016. Results: Sixteen references were included in the Portuguese and English languages, which addressed the use of the ICF in occupational health, regardless of the type of application. Conclusions: The search for the operationalization and simplification of the International Classification of Functioning, Disability and Health remains an important focus of the studies that aim its use in evaluating the worker's functionality and incapacities, being the occupational health one of the promising areas of ICF application. 